\title{
2006-1014: MISCONCEPTIONS ABOUT RATE PROCESSES: PRELIMINARY EVIDENCE FOR THE IMPORTANCE OF EMERGENT CONCEPTUAL SCHEMAS IN THERMAL AND TRANSPORT SCIENCES
}

\author{
Ronald Miller, Colorado School of Mines \\ RONALD L. MILLER is professor of chemical engineering at the Colorado School of Mines \\ where he has taught chemical engineering and interdisciplinary courses and conducted research in \\ educational methods for the past twenty years. He has received three university-wide teaching \\ awards and has held a Jenni teaching fellowship at CSM. He has received grant awards for \\ educational research from the National Science Foundation, the U.S. Department of Education \\ (FIPSE), the National Endowment for the Humanities, and the Colorado Commission on Higher \\ Education.
}

\section{Ruth Streveler, Colorado School of Mines}

RUTH A. STREVELER is the Director of the Center for Engineering Education at the Colorado School of Mines and Associate Research Professor in Academic Affairs. Dr. Streveler received her Ph.D. in Educational Psychology from the University of Hawaii at Manoa. She also holds a Master of Science in Zoology from the Ohio State University and a Bachelor of Arts in Biology from Indiana University at Bloomington. She is co-principle investigator of three NSF-sponsored projects: Developing an Outcomes Assessment Instrument for Identifying Engineering Student Misconceptions in Thermal and Transport Sciences (DUE - 0127806), Center for the Advancement of Engineering Education (ESI-0227558), and Rigorous Research in Engineering Education: Creating a Community of Practice (DUE-0341127).

\section{Barbara Olds, National Science Foundation and Colorado School of Mines}

BARBARA M. OLDS is Professor of Liberal Arts and International Studies at the Colorado School of Mines. She has participated in a number of curriculum innovation projects and has been active in the engineering education and assessment communities. She was a Fulbright lecturer/researcher in Sweden in 1999. Dr. Olds is presently serving as Director of the Division of Research, Evaluation and Communication in the EHR Directorate of the National Science Foundation.

\section{Michelene Chi, University of Pittsburgh}

MICHELENE T.H. CHI is Senior Scientist in the Learning Research and Development Center and Professor of Psychology at the University of Pittsburgh. With degrees in mathematics and psychology from Carnegie-Mellon University, her research interests focus on student learning and understanding of scientific concepts, cognitive assessment of learning, and the effectiveness of tutoring. Her paper entitled "Categorization and Representation of Physics Problems by Experts and Novices" published in 1981 established the field of expert/novice studies and is the most cited publication in Cognitive Science.

\section{Mary Nelson, University of Colorado}

MARY A. NELSON received her Masters degree in Mathematics from George Mason University and her $\mathrm{PhD}$ in the Research and Evaluation Methods from the University of Colorado, Boulder working with Dr. Lorrie Shepard. Mary has taught math at the middle school, high school, and college levels for 35 years and is presently conducting research on three funded grants studying how to transform introductory college science and mathematics courses, how to improve K-12 mathematics teaching, and assessing engineering student misconceptions in thermal and transport sciences. 
MONICA R. GEIST is a doctoral student in the Applied Statistics and Research Methods program at the University of Northern Colorado. Monica has taught math at the college level for 15 years. Monica is presently conducting research on engineering student misconceptions in electrical and mechanical engineering. 


\title{
Misconceptions about Rate Processes: Preliminary Evidence for the Importance of Emergent Conceptual Schemas in Thermal and Transport Sciences
}

\author{
Ronald L. Miller, Ruth A. Streveler, Barbara M. Olds \\ Colorado School of Mines \\ Michelene T. H. Chi \\ University of Pittsburgh \\ Mary A. Nelson, Monica R. Geist \\ University of Colorado/University of Northern Colorado
}

\begin{abstract}
This paper reports preliminary evidence that a significant number of engineering students possess robust misconceptions about rate processes such as transfer of heat even after years of study in thermal and transport sciences including fluid mechanics, heat transfer, and thermodynamics. Data from the Thermal and Transport Concept Inventory (TTCI) currently under development and additional questions specifically written for the present study are reported and analyzed. Results indicate the presence of a persistent misconception about the relationship between the rate of heat transfer and amount of energy transferred in processes of engineering interest. We use the emergent theory developed by Chi and colleagues to propose a possible explanation for these findings.
\end{abstract}

\section{Introduction}

With funding from the National Science Foundation (DUE-0127806), our research team is completing development of a concept inventory instrument to measure engineering students' understanding of difficult concepts in thermal and transport sciences (e.g. heat transfer, fluid mechanics, thermodynamics). [1-4] Version 2.21 of the instrument, known as the Thermal and Transport Concept Inventory (TTCI) has been beta-tested at six United States engineering institutions and psychometric results have been used to test instrument validity and reliability. Preliminary beta test results from this facet of the instrument development have been reported previously. [4] Nine of the original 32 questions did not perform at expected levels of reliability and have been replaced in version 3.0 of the TTCI. Additional beta testing is on-going and will be completed before wide-spread dissemination of the instrument via the web scheduled for mid-2006.

As part of our psychometric work, we use factor analysis and cross-tabulations to identify common misconceptions which are robust and which transfer across question contexts and disciplines (e.g. fundamental misconceptions which exist in, say, both fluid mechanics and heat transfer). The goal of this analysis is to identify student misconceptions which can be repaired in one context with the expectation of far transfer to other disciplinary contexts students might be expected to encounter. So far, this 
technique has allowed us to identify and group three overall categories of misconceptions:

- energy vs. temperature

- steady-state vs. equilibrium processes

- rate vs. amount of transfer (e.g. heat transfer, momentum transfer, mass transfer)

Details about the first two misconceptions were reported previously [4] and results indicated that at least $10-20 \%$ of engineering students in the study did not understand how energy and temperature were related by heat capacity or when processes could be considered at equilibrium. In this paper, we report preliminary evidence that a significant number of engineering students (many of whom have completed courses in fluid mechanics, heat transfer, thermodynamics, and/or transport phenomena) also possess a fundamental misconception about the relationship between rate of energy transfer and the amount of energy transferred in various heat transfer processes and contexts.

For purposes of the following discussion and throughout this paper, all concept questions referenced are included in Appendix A (for convenience, each question has been coded with an italicized keyword reference).

Initial evidence for existence of the "rate vs. amount" heat transfer misconception. As the data from the TTCI beta testing were analyzed, we noticed several heat transfer questions were yielding far fewer numbers of correct responses than we expected. For example, Table I shows a cross-tabulation for TTCI beta test results from the Meltice and Carpet questions. In such a table, we can see frequency counts of how many students selected each answer for the two posed questions. By observing the individual entries in each row and column, we can determine how many students answered both questions correctly. More importantly, when students choose incorrect but conceptually-related wrong answers (known as distractors), we have obtained evidence of a misconception which is robust enough to carry across the context of both questions. In the case of twopart questions like Meltice, we also obtain evidence of reliability when a large proportion of students answer each question consistently (that is, they select both correct answers or select a pair of distractors that are logically related).

Results in Table I indicate that only $18 \%$ of the beta test students answered both the MeltIce 1 and Carpet questions correctly and only 19\% answered both the Meltice 2 and Carpet questions correctly. Overall, $27 \%$ of the students correctly answered the MeltIce 1 question, $24 \%$ identified the correct reason (Meltice 2 ), and $\sim 64 \%$ correctly answered the Carpet question. Of interest is the significant number of students (approximately 13\%) who incorrectly answered all three questions by selecting distractors that provide evidence for the existence of the same misconception ("a" for MeltIce1, "e" for MeltIce2, and "d" for Carpet). 
In the Meltice question, the "a,e" combination of distractors was chosen by students who think the process of melting ice with hot blocks is governed by the rate of melting rather than the amount of energy that will be transferred from blocks to ice. Distractor " $\mathrm{d}$ " for the Carpet question was chosen by students who incorrectly believe that carpet and tile are at different temperatures because of differences in the rate of convective heat transfer off the two surfaces rather than considering the amount of energy transferred into tile or carpet from a bare human foot. These results were our first indication of the "rate vs. amount" misconception in students who beta-tested the TTCI instrument.

Table I - Cross-Tabulation of Student Responses to MeltIce1, MeltIce2 and Carpet Questions $^{1}$

\begin{tabular}{|c|c|c|c|c|c|}
\hline & \multicolumn{4}{|c|}{ Carpet responses } & \multirow{2}{*}{ Total } \\
\hline & $\mathrm{a}$ & $\mathrm{b}$ & $\mathrm{c}($ correct $)$ & $\mathrm{d}$ & \\
\hline \multicolumn{6}{|l|}{$\begin{array}{l}\text { MeltIce } 1 \\
\text { responses }\end{array}$} \\
\hline $\mathrm{a}$ & 6 & 1 & 33 & 15 & 55 \\
\hline $\mathrm{b}$ & 3 & 0 & 12 & 4 & 19 \\
\hline c (correct) & 5 & 0 & 21 & 6 & 32 \\
\hline $\mathrm{d}$ & 2 & 0 & 8 & 1 & 11 \\
\hline Total & 16 & 1 & 74 & 26 & 117 \\
\hline \multicolumn{6}{|l|}{$\begin{array}{l}\text { MeltIce2 } \\
\text { responses }\end{array}$} \\
\hline e & 5 & 1 & 30 & 15 & 51 \\
\hline $\mathrm{f}($ correct $)$ & 3 & 0 & 21 & 3 & 27 \\
\hline $\mathrm{g}$ & 3 & 0 & 13 & 5 & 21 \\
\hline $\mathrm{h}$ & 1 & 0 & 1 & 0 & 2 \\
\hline $\mathrm{i}$ & 3 & 0 & 8 & 1 & 12 \\
\hline Total & 15 & 1 & 73 & 24 & 113 \\
\hline
\end{tabular}

${ }^{1}$ yellow cells are located in rows and columns of the correct response to each question; the blue cell represents an example distractor pair which indicates persistent misconceptions in significant numbers of student respondents. In this example, 15 students chose distractor 'a' on the MeltIcel question and distractor 'd' on the Carpet question. By comparing these two distractors, incorrect ideas (or misconceptions) about the concepts can be recognized.

Cross-tab analysis of beta results for other heat transfer questions in the TTCI also indicated the presence of the "rate vs. amount" misconception. For example, $\sim 17 \%$ of students answering the HotPlate question selected answer " $\mathrm{e}$ " which indicates an inability to link the rate of fluid heating with the amount of energy added to the fluid and its relationship to fluid heat capacity. About $40 \%$ of these students also answered " $d$ " for the Carpet question, once again indicating conceptual confusion focusing on the rate of convective heat transfer off the two floor surfaces rather than considering the amount of energy transferred into tile or carpet from a bare human foot. 
Finally, we found that $\sim 55 \%$ of the students selecting distractors "c" or "e" for the Hotplate question also choose the "a,e" distractor pair for the Meltice questions. This combination of results again suggests conceptual difficulties with the relationship between temperature change, the amount of energy transferred, and the rate of transfer. Amount and rate are concepts in two different ontological categories, substances and processes, respectively. Chi, Slotta and de Leeuw [5] have proposed that students often misconceive process concepts as substance concepts. Furthermore, Slotta et al. found that physics novices adopted such substance-based conceptualizations across a broad range of topics including light, heat, and electricity. [6]

Based on these early findings, we developed additional questions designed specifically to probe for conceptual understanding of heat transfer rate vs. the amount of transferred energy in several simple heat transfer processes. The new questions contained both multiple-choice responses (the correct answer plus several distractors based on expected student misconceptions) and open-ended responses to allow students to explain and justify their answers. We used these comments to help understand the nature of the "rate vs. amount" misconception in this student cohort.

The purpose of this paper is to provide the results from this extended study and to speculate on why some engineering students still possess the "rate vs. amount" misconception even after completing significant coursework in thermal science and transport processes.

\section{Participants and Methods}

Data reported in this study come from two sources: 1) TTCI beta test data from the Thermal and Transport Concept Inventory (TTCI) presently under development and 2) additional concept inventory data using new questions specifically focused on the "rate/amount" misconception.

For ease of beta testing, version 2.21 of the original 32-question multiple-choice TTCI was divided into subsets for heat transfer (6 questions), fluid mechanics (12 questions), and thermodynamics (13 questions). Approximately 120 undergraduate engineering students ranging from sophomores to seniors at six U.S. engineering schools answered the heat transfer portion of the TTCI. Nearly all of the participants had completed at least one course in thermal or transport sciences (e.g. heat transfer, fluid mechanics, thermodynamics).

The new question set was administered to 29 chemical engineering seniors, all of whom had completed courses in fluid mechanics, heat transfer, thermodynamics ( 2 courses), mass transfer, and an integrated transport phenomena course. These students also answered 3 heat transfer questions from the TTCI (Meltice, Carpet, Hotplate) to compare their performance with the TTCI beta test results. 


\section{Results and Analysis}

In this section, we report findings from the study using 29 chemical engineering seniors. So that we could anchor these new data with previously collected results from the TTCI beta test reported above and in previous papers [3,4], we administered the Meltice, Carpet, and Hotplate questions to the chemical engineering test group. Results of this comparison are shown in Table II.

Table II - Comparison of Responses to Selected TTCI Questions

\begin{tabular}{|l|c|c|}
\hline Question & $\begin{array}{c}\text { TTCI Beta Test Results }(\mathrm{n}=117), \\
\text { \% correct responses }\end{array}$ & $\begin{array}{c}\text { ChE Students in Present Study } \\
(\mathrm{n}=29), \\
\text { \% correct responses }\end{array}$ \\
\hline Meltice1 & 27.4 & 37.9 \\
\hline Meltice2 & 23.9 & 37.9 \\
\hline Carpet & 63.2 & 55.2 \\
\hline Hotplate & 47.9 & 62.1 \\
\hline
\end{tabular}

With the exception of the Carpet question, the chemical engineering group of senior students performed statistically better that the TTCI beta test group which consisted of a mixture of sophomore, junior, and senior mechanical and chemical engineering students. Thus, Table II provides preliminary evidence that traditional instruction in thermal science and thermodynamics courses can help some students repair some misconceptions about heat and heat transfer including the rate/amount misconception. However, the results in Table II also clearly show that significant numbers of senior-level engineering students persist in their misconceptions about rates and amounts of heat transfer, even after completed several thermal science courses including a transport phenomena course which specifically discusses and models rate processes in great detail.

To further explore this finding, we administered to the chemical engineering test group additional questions focusing specifically on heat transfer rates vs. the amount of energy transferred. Key results for these questions are shown in Table III.

Table III - Results of Chemical Engineering Student Responses to "Rate vs. Amount" Questions

\begin{tabular}{|l|c|c|}
\hline \multicolumn{1}{|c|}{ Question } & \% correct responses & $\begin{array}{c}\text { Most commonly chosen } \\
\text { distractor } \\
\text { and \% of students who choose it }\end{array}$ \\
\hline Heatblock1 & 96.6 & --- \\
\hline Heatblock2 & 75.9 & $\mathrm{f}(17 \%)$ \\
\hline Househeat & 17.2 & $\mathrm{a}(55 \%)$ \\
\hline Twohouse1 & 96.6 & --- \\
\hline Twohouse2 & 48.3 & $\mathrm{f}(28 \%)$ \\
\hline
\end{tabular}


The Heatblock question was designed to verify results originally obtained using the Hotplate question summarized in Table II. Hotplate results indicated a significant number of chemical engineering seniors $(\sim 38 \%)$ could not identify the relationship between the amount of time each fluid (water and ethanol) was heated and the amount of energy added to the fluid. Approximately $10 \%$ indicated that each fluid received the same amount of energy since the change in temperature was the same for each and thus, ignored the amount of time each fluid was heated at the same rate. Another $17 \%$ believed that they couldn't answer the question without heat capacity data even though the information given could be used to determine the relative size of each fluid's heat capacity. As indicated in Table II, slightly fewer chemical engineering seniors missed the Hotplate question, but the misconception persists.

Interestingly, $\sim 86 \%$ ( 6 out of 7 ) of the chemical engineering students who incorrectly answered the Heatblock 2 question also missed the Hotplate question and conversely $\sim 55 \%$ ( 6 out of 11) of the students missing the Hotplate question also missed Heatblock2. The correlation coefficient for the (Heatblock2, Hotplate) correct answer pair $(\mathrm{e}, \mathrm{a})$ and conceptually related distractor pairs $(\mathrm{f}, \mathrm{c})$ and $(\mathrm{b}, \mathrm{d})$ was 0.45 indicating that the rate/amount misconception is held by a significant number of these students across contexts.

It is possible to argue that some students may be confused by Hotplate if they consider other heat transfer effects such as liquid evaporation or convection. The Heatblock question was designed to eliminate this potentially confounding effect by focusing on heating of solid blocks rather than liquid samples. As the results in Table III indicate, nearly every student was able to identify which block was heated faster but $\sim 24 \%$ still could not identify which received more energy during the heating process. Most of the students incorrectly answering Heatblock indicated that both blocks received the same amount of energy, a result that agrees closely with the Hotplate results we've observed. These data once again indicate the persistence of student confusion about the relationship (or lack of) between the rate at which a body is heated and the amount of energy it absorbs.

Students answering Heatblock were asked to explain and justify their multiple-choice answers. The following excerpts show how students get confused about the rate/amount concept:

"The rate of heating is faster for block 1 , so it has more energy transferred."

"Because they [the blocks] eventually reached the same temperature, the same amount of energy is transferred."

"If the blocks have the same heat transfer coefficient and same heat transfer rate, the amount of energy transferred must be the same." 
The Househeat question was developed based on a discussion about mental models in Don Norman's book about the design of everyday objects. [7] He mentioned that most of us consider an ordinary house thermostat as a device which controls the rate of heating when in fact (ignoring the new "intelligent" thermostats which can anticipate achieving a temperature setpoint and turn off the furnace before the temperature is reached) a thermostat is simply an on-off switch to control the amount of energy delivered to the house. As Table III indicates, nearly $83 \%$ of the chemical engineering seniors in this study also believed that a thermostat will heat more rapidly if the setpoint is far above the desired house temperature.

Clearly, an engineering education does not repair the misconception that a simple thermostat controls the rate of heating rather than the amount of heating as the following student explanations of their Househeat answers illustrate:

"Faster heating gives more energy into the house."

"A higher setting will blow out air and energy at a higher rate."

"The thermostat controls the power output so a higher setting gives more power."

Finally, the Twohouse question was developed to ask another seemingly simple question about the relationship between the rate of heat loss in insulated and uninsulated houses and the amount of energy required to reheat both houses to the same temperature. As the results in Table III show, the chemical engineering students studied nearly all correctly indicated that the uninsulated house will cool faster from $20{ }^{\circ} \mathrm{C}$ towards the atmosphere temperature of $0{ }^{\circ} \mathrm{C}$ once the furnace stopped working. However, only $48 \%$ correctly believed that both houses would require the same amount of energy to be reheated from 0 ${ }^{\mathrm{O}} \mathrm{C}$ to $20{ }^{\mathrm{O}} \mathrm{C}$ with another $\sim 28 \%$ indicating that the uninsulated house would require more energy to reheat since they believe it lost more energy during the cool down process. Thus, a significant number of the students persist in their belief that the house which cooled faster also lost a larger amount of energy.

\section{Theoretical Framework}

Clearly, the results presented in this paper indicate that some engineering students (including seniors who have completed several relevant thermal and transport science courses) still do not understand key relationships between heat transfer rates and the amount of energy transferred in simple processes. Our prior research has also shown that other important misconceptions involving energy quality (using a $2^{\text {nd }}$ law of thermodynamics analysis), heat transfer mechanisms, mechanisms of momentum transfer, the difference between energy and temperature, and differences between steadystate and equilibrium processes also persist in our students. [4] 
One might ask how this can be so. How can intelligent and well-educated engineering students possess overly simplistic conceptualizations of foundational conceptions like the transfer of molecular kinetic energy (heat) and other related processes involving electric current, molecular diffusion, and entropy? Simply suggesting that more instruction and practice is needed apparently does not provide a strategy to repair these robust misconceptions, given the results of seniors studied in this project. This suggests that some students are using simplified cause-and-effect explanations of phenomena (likely formed in childhood) rather than understanding the true complex and systemic nature of these conceptions.

Such complex and systemic processes are not causal in nature, but rather, they develop in intricate, mutually-dependent ways. These concepts have been studied in recent cognitive research which has addressed the question of why these concepts are challenging for students and so resistant to repair using traditional teaching techniques and curricular materials. Professor Michelene Chi and her colleagues have identified a particular class of concepts, called Emergent Processes, that are resistant to traditional instruction. [8,9] Emergent Processes are those properties of a system that result from its constituent elements interacting over time, often in conjunction with equilibration. Concepts of this type are found in many science disciplines, including biology (e.g., natural selection, flight formations of bird flocks), physics and engineering (e.g., heat transfer, diffusion, momentum transfer in fluids, electric current), economics (e.g., inflation, supply and demand) and everyday life (e.g. traffic jams).

Chi has argued that Emergent Processes are the most difficult concepts for students to learn for two reasons. [10,11] First, the systemic nature of these concepts is unfamiliar to students, making them difficult to correctly classify according to some established schema. Second, Emergent Processes often suggest a misleading simple causal interpretation that leads students to wrongly interpret the concepts as direct causal processes rather than as emergent ones. For example, Slotta, Chi, and Joram [12] found that physics novices tend to view heat transfer, which is actually a complex equilibration process of molecular kinetic energy within a system, as the flow of a substance called "heat" from one object to another. This flow is often mistakenly explained by students as an increase in the amount of hot molecules (or hot substances) moving from one object to the other, rather than as an increase in the speed (or rate) of molecular movement. Amount versus rate explanations are also given as reasons for changes due to natural selection. [13] For example, students misconceive the pattern of moths getting darker with industrialization as the number of dark moths increasing over generations, rather than the proportion of dark moths increasing over generations.

"Amount" is clearly a substance-based conception. Reiner, Slotta, Chi and Resnick [14] reviewed the research literature on misconceptions in physics, and found an underlying commitment to substance-based misconceptions (i.e. that force is a substance transferred between bodies; that heat is a substance that flows from hot to cold bodies). They define a substance-based schema to include the following properties which students will incorporate into their mental model of heat transfer processes: 
1. substances can push or be pushed

2. substances experience drag when moving in contact with a solid surface

3. substances are containable

4. substances can be used up

5. substances have a definite location

6. substances are able to move or be moved

7. substances are stable

8. substances have surfaces and volume

9. substances are additive

10. substances require a force to accelerate

11. substances respond to gravitational forces

This means that a student applying a substance-based schema to the process of energy transfer will believe that heat and cold are inherent properties of physical objects, that heat has a physical location and transfers from object to object, and that heat will accumulate in a body and be contained. The notion that heat can accumulate in a body (property 9 above) reinforces our interpretation that heat flow occurs when there is an increase in the amount of heat molecules. According to Chi's theory, these students will not view heat transfer as a constraint-based process involving transfer of energy (but not necessarily mass) and therefore, a misconception will be formed because of the ontological mismatch. Use of common language such as "heat flow," "shut the door, you're letting the heat out" or "weatherstripping doors and windows will help keep heat in" only serves to reinforce the misconception.

Based on Chi's theory, we propose that engineering students who still possess a substance-based schema for heat transfer will view heat as a flowing entity much as they view water flowing in a pipe. (This type of analogy, especially for fluid flow and electric current "flow" is prevalent in engineering textbooks). They will then readily equate a higher rate of flow with a larger amount of transfer, just as described in the Heatblock quotes presented in the previous section. The same misconception is even more apparent in the Househeat question where $\sim 83 \%$ of students incorrectly viewed the thermostat as a rate-controlling device (i.e. able to change the rate of heat transfer into the house in some fashion) rather than an on-off device where only the amount of heating is controlled depending upon the time that the furnace runs. Again, the link to viewing heat as a substance is clear from the student quotes in which they often mention heating rates and power delivery (power is the rate of using or delivering energy). We see the same substance-based schema appear in responses to the Twohouse question for those students who can correctly select the uninsulated house as the one cooling faster but incorrectly predict that the uninsulated lost a larger amount of heat during cooling. 


\section{Conclusions/Implications}

Beta test data from the Thermal and Transport Concept Inventory (TTCI) collected at six engineering schools of varying size, demographics, and geographical location has been used to identify the presence of a persistent engineering student misconception about the relationship between the rate of heat transfer and amount of energy transferred.

Additional questions have been developed and data collected with a cohort of senior chemical engineering students. Results again indicate that a significant number of the students make incorrect predictions about the behavior of simple heat transfer processes even after completing $\sim 6$ courses in thermal and transport sciences. We suggest that Chi's theory of emergence processes involving the incorrect use of substance-based schema to describe processes such as heat transfer provides an explanation for the existence and robustness of this misconception in our students.

To achieve our ultimate goal of both identifying and repairing fundamental thermal and transport science misconceptions, our next step will be to apply the schema training methods of Chi and Slotta to help engineering students replace the strongly-held but incorrect substance schema with more appropriate models based on emergent processes. This work will begin during the summer of 2006 funded by NSF.

\section{Acknowledgment}

We wish to thank the National Science Foundation for supporting this work through grant number DUE-0127806 which funds "Developing an Outcomes Assessment Instrument for Identifying Engineering Student Misconceptions in Thermal and Transport Sciences."

\section{References}

[1] http://www.mines.edu/research/cee/Misconceptions.html

[2] Streveler, R.A., Olds, B.M., Miller, R. L. \& Nelson, M.A. (June, 2003). 'Using a Delphi Study to Identify the Most Difficult Concepts for Students to Master in Thermal and Transport Science." Proceedings of the Annual Conference of the American Society for Engineering Education, Nashville, Tennessee.

[3] Olds, B. M., Streveler, R. A., Miller, R. L., \& Nelson, M. A. (June, 2004). "Preliminary Results from the Development of a Concept Inventory in Thermal and Transport Science." Proceedings of the Annual Conference of the American Society for Engineering Education, Salt Lake City, Utah.

[4] Miller, R.L., Streveler, R.A., Nelson, M.A., Geist, M.R., and Olds, B.M. (June, 2005). "Concept Inventories Meet Cognitive Psychology: Using Beta Testing as a Mechanism for Identifying Engineering Student Misconceptions." Proceedings of the American Society for Engineering Education Annual Conference, Portland, Oregon.

[5] Chi, M. T. H., Slotta, J. D. and de Leeuw, N. (1994). From Things to Processes: A Theory of Conceptual Change for Learning Science Concepts. Learning and Instruction, 4, 27-43. 
[6] Slotta, J. D. \& Chi, M. T. H., and Joram, E. (1995). Assessing Students' Misclassifications of Physics Concepts: An Ontological Basis for Conceptual Change. Cognition and Instruction. 13, (3), 373-400.

[7] Norman, D.A. (2002). The Design of Everyday Things. New York: Basic Books.

[8] Chi, M. T. H. (1993). Barriers to Conceptual Change in Learning Science Concepts: A Theoretical Conjecture. In W. Kintsch (Ed.), Proceedings of the Fifteenth Annual Cognitive Science Society Conference (pp. 312-317). Hillsdale, NJ: Erlbaum

[9] Chi, M. T. H. (1992). Conceptual Change Within and Across Ontological Categories: Examples from Learning and Discovery in Science. In R. Giere (Ed.), Cognitive Models of Science: Minnesota Studies in the Philosophy of Science. (pp.129-160). Minneapolis, MN: University of Minnesota Press.

[10] Chi, M.T.H. (2005). Commonsense Conceptions of Emergent Processes: Why Some Misconceptions Are Robust. Journal of the Learning Sciences, 14(2), 161-199.

[11] Chi, M. T. H. (1997). Creativity: Shifting Across Ontological Categories Flexibly. In T. B. Ward, S. M. Smith, \& J. Vaid (Eds.), Creative thought: An investigation of conceptual structures and processes (pp.209-234). Washington, DC: American Psychological Association.

[12] Slotta, J.D., Chi, M.T.H., and Joram, E. (1995). Assessing Students' Misclassifications of Physics Concepts: An Ontological Basis for Conceptual Change. Cognition and Instruction. 13 (3), 373-400.

[13] Chi, M.T.H., Kristensen, A.K., \& Roscoe, R. (Submitted). Misunderstanding Emergent Causal Mechanism in Natural Selection. Educational Research Review.

[14] Reiner, M., Slotta, J. D., Chi, M. T.H., and Resnick, L. B. (2000). "Naive Physics Reasoning: A Commitment to Substance-Based Conceptions," Cognition and Instruction, Volume 18, Number 1, 1-43.

\section{Biographical Sketches}

RONALD L. MILLER is professor of chemical engineering at the Colorado School of Mines where he has taught chemical engineering and interdisciplinary courses and conducted research in educational methods for the past twenty years. He has received three university-wide teaching awards and has held a Jenni teaching fellowship at CSM. He has received grant awards for educational research from the National Science Foundation, the U.S. Department of Education (FIPSE), the National Endowment for the Humanities, and the Colorado Commission on Higher Education.

RUTH A. STREVELER is the Director of the Center for Engineering Education at the Colorado School of Mines and Associate Research Professor in Academic Affairs. Dr. Streveler received her Ph.D. in Educational Psychology from the University of Hawaii at Manoa. She also holds a Master of Science in Zoology from the Ohio State University and a Bachelor of Arts in Biology from Indiana University at Bloomington. She is co-principle investigator of three NSF-sponsored projects: Developing an Outcomes Assessment Instrument for Identifying Engineering Student Misconceptions in Thermal and Transport Sciences (DUE - 0127806), Center for the Advancement of Engineering Education (ESI-0227558), and Rigorous Research in Engineering Education: Creating a Community of Practice (DUE-0341127).

BARBARA M. OLDS is Professor of Liberal Arts and International Studies at the Colorado School of Mines. She has participated in a number of curriculum innovation projects and has been active in the 
engineering education and assessment communities. She was a Fulbright lecturer/researcher in Sweden in 1999. Dr. Olds is presently serving as Director of the Division of Research, Evaluation and

Communication in the EHR Directorate of the National Science Foundation.

MICHELENE T.H. CHI is Senior Scientist in the Learning Research and Development Center and Professor of Psychology at the University of Pittsburgh. With degrees in mathematics and psychology from Carnegie-Mellon University, her research interests focus on student learning and understanding of scientific concepts, cognitive assessment of learning, and the effectiveness of tutoring. Her paper entitled "Categorization and Representation of Physics Problems by Experts and Novices" published in 1981 established the field of expert/novice studies and is the most cited publication in Cognitive Science.

MARY A. NELSON received her Masters degree in Mathematics from George Mason University and her $\mathrm{PhD}$ in the Research and Evaluation Methods from the University of Colorado, Boulder working with Dr. Lorrie Shepard. Mary has taught math at the middle school, high school, and college levels for 35 years and is presently conducting research on three funded grants studying how to transform introductory college science and mathematics courses, how to improve K-12 mathematics teaching, and assessing engineering student misconceptions in thermal and transport sciences.

MONICA R. GEIST is a doctoral student in the Applied Statistics and Research Methods program at the University of Northern Colorado. Monica has taught math at the college level for 15 years. Monica is presently conducting research on engineering student misconceptions in electrical and mechanical engineering. 


\section{Appendix A}

\section{List of Heat Transfer Questions Discussed in This Paper}

Note: Reliability and validity not fully established for all questions. The TTCI is not yet available for general use.

\section{MeltIce Questions}

You are in the business of melting ice at $0^{\circ} \mathrm{C}$ using hot blocks of metal as an energy source. One option is to use one metal block at a temperature of $200^{\circ} \mathrm{C}$ and a second option is to use two metal blocks each at a temperature of $100^{\circ} \mathrm{C}$.

All the metal blocks are made from the same material and have the same weight and surface area.

(MeltIce1) Which option will melt more ice?
a. the $100{ }^{\mathrm{O}} \mathrm{C}$ blocks
b. the $200{ }^{\mathrm{O}} \mathrm{C}$ block
c. either option will melt the same amount of ice
d. can't tell from the information given

(MeltIce2) because:

e. 2 blocks have twice as much surface area as 1 block so the energy transfer rate will be higher when more blocks are used

f. energy transferred is proportional to the mass of blocks used and the change in block temperature during the process

g. using a higher temperature block will melt the ice faster because the larger temperature difference will increase the rate of energy transfer

h. the temperature of the hotter block will decrease faster as energy is transferred to the ice

i. the heat capacity of the metal is a function of temperature 


\section{Carpet Question}

An engineering student walking barefoot (without shoes or socks) from a tile floor onto a carpeted floor notices that the tile feels cooler than the carpet.

Which of the following explanations seems like the most plausible way to explain this observation?

a. The carpet has a slightly higher temperature because it retains energy from the room better since the carpet contains air between the fibers and air is a good insulator.

b. The carpet has more surface area in contact with the student's foot than the tile does, so the carpet is heated faster and feels hotter.

c. The tile conducts and stores energy better than the carpet, so more energy moves away from the student's foot on tile than carpet.

d. The rate of heat transfer by convection (air movement) is different for tile and carpet. 


\section{Hotplate Question}

Two identical beakers contain equal masses of liquid at a temperature of $20{ }^{\circ} \mathrm{C}$ as shown below. One beaker is filled with water and the other beaker is filled with ethanol (ethyl alcohol). The temperature of each liquid is increased from $20{ }^{\circ} \mathrm{C}$ to $40{ }^{\circ} \mathrm{C}$ using identical hot plates.

It takes 2 minutes for the ethanol temperature to reach $40{ }^{\circ} \mathrm{C}$ and 3 minutes for the water to reach $40{ }^{\circ} \mathrm{C}$. Once a liquid had reached $40{ }^{\circ} \mathrm{C}$, its hot plate is turned off.

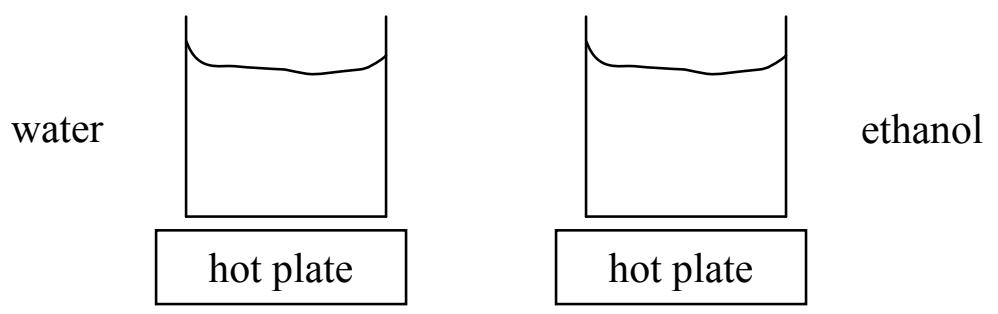

To which liquid was more energy transferred during the heating process?

a. Water because more energy is transferred to the liquid that is heated longer.

b. Alcohol because more energy is transferred to the liquid that heats up faster (temperature rises faster).

c. Both liquids received the same amount of energy because they started at the same initial temperature and ended at the same final temperature.

d. Can't determine from the information given because heat transfer coefficients for water and ethanol are needed.

e. Can't determine from the information given because heat capacities of water and ethanol are needed. 


\section{Heatblock Question}

Two metal blocks initially at room temperature are heated in a furnace operating at 100 ${ }^{\mathrm{O}} \mathrm{C}$.

Block 1 reaches a temperature of $100{ }^{\circ} \mathrm{C}$ in 5 minutes while block 2 takes 10 minutes to reach $100{ }^{\circ} \mathrm{C}$.

(Heatblock1) Which block heated faster?
a. block 1
b. block 2
c. same rate for each block

(Heatblock2) To which block was more energy transferred?
d. block 1
e. block 2
f. same amount for each block

Explain the reasoning for your answers: 


\section{Househeat Question}

You enter a cold room in a house and adjust the thermostat to heat the room to a more comfortable level.

If you want the room temperature to increase quickly, should you set the thermostat setting to the desired temperature or much higher than the desired temperature?
a. All the way up
b. Set to desired temp
c. Either setting will heat the room at the same rate
d. Can't determine

Explain the reason for your answer: 


\section{Twohouse Question}

Two houses of identical size and shape sit side by side on a street. One house is insulated but the other is not. The temperature inside each house is $68{ }^{\circ} \mathrm{F}\left(20^{\circ} \mathrm{C}\right)$.

If electrical power to the houses is lost so that the furnace and thermostat don't work and the outside air temperature is $32^{\circ} \mathrm{F}\left(0^{\circ} \mathrm{C}\right)$, which house will cool off faster?

a. Both houses will cool at the same rate because they are the same size so have the same surface area for heat transfer

b. The insulated house will cool faster because typical insulation materials like fiberglass actually conduct heat quickly

c. The uninsulated house will cool faster because insulation in the other house will reduce the rate of heat transfer to the atmosphere

After a week of no heat, both houses have cooled to the temperature of the atmosphere which is still $32{ }^{\circ} \mathrm{F}\left(0^{\circ} \mathrm{C}\right)$. When electrical power to both houses is restored and the houses are quickly heated back to $68^{\mathrm{O}} \mathrm{F}\left(20^{\circ} \mathrm{C}\right)$, to which house must more energy be supplied to recover from the outage?

d. Both houses will require essentially the same amount of energy because they start at the same cold temperature and are warmed to the same higher temperature

e. The insulated house will require more energy because it is harder to heat up insulation

f. The uninsulated house will require more energy since it lost more energy during the power outage

g. Can't determine because the amount of energy initially lost from each house is not known 